\title{
Creating a Digital Card of Local Culture from the View of the Belt and Road- Taking Innovative Design Thinking of Zhenjiang Cultural and Creative Products as an Example
}

\author{
Wang Liwen ${ }^{1}$ \\ ${ }^{1}$ Department of Industrial Design, School of Arts, Jiangsu University, Zhenjiang, China
}

\begin{abstract}
The further refinement and external transmission of local cultural characteristics and core values is a brand-new way of promoting local cultural development under the opportunity of multi-cultural exchanges under the Belt and Road Initiative. Taking the innovative design thinking of Zhenjiang cultural and creative products as an example, this paper discusses how to make better use of local traditional cultural resources, starting with cultural and creative products, illustrate their modern value during inheritance and protection and create a digital card of Zhenjiang culture to facilitate cross-cultural exchange and transmission effectively, improve the urban competitiveness of Zhenjiang and establish a good city image, thus promoting the local culture of Zhenjiang to the world.
\end{abstract}

\section{INTRODUCTION}

As the Chinese government continues to promote the Belt and Road strategy, the construction of local culture, the dissemination of city image and the creation of culture card are becoming increasingly important. This is not only a way to find the right position and work hard in the new round of opening up of the Belt and Road, but also a brand new way to promote the local cultural development. This paper takes the innovative design thinking of Zhenjiang cultural and creative product as an example, discusses how to sort out and integrate cultural resources, excavate and refine local cultural elements of Zhenjiang that are representative, popular, and have aesthetic imagery, thus developing the design of Zhenjiang cultural and creative products with target and creating a digital card of Zhenjiang culture through design innovation in the context of the Belt and Road strategy.

\section{BRIEF ANALYSIS ON THE BELT AND ROAD CULTURAL CONSTRUCTION AND THE BACKGROUND OF CULTURAL AND CREATIVE INDUSTRIES IN ZHENJIANG}

The Belt and Road (B\&R) has become a basic state policy of China for future development from a grand idea since President Xi Jinping put forward the cooperation initiative of jointly building the B\&R in Kazakhstan in 2013. The B\&R strategy has not only brought about further economic growth, but also enhanced the development of national soft power. The promotion and transmission of Chinese culture is an effective way to enhance the soft power of China and an important support for the implementation of the B\&R strategy.

The B\&R construction has provided huge development space and historical opportunities for the promotion of local culture and the development of local cultural industries. The further refinement and external transmission of local cultural characteristics and core values is a brand-new way of promoting local cultural development. Zhenjiang, located at the intersection of the Belt and Road and in the center of the Yangtze River Economic Belt, has unique geographical advantages, a sound development foundation and, in particular, profound humanistic connotations, rich cultural resources and unique conditions. We should make better use of traditional cultural resources and illustrate their modern value while inheriting and protecting historical cultural resources in Zhenjiang to promote its local culture to the world under the opportunity of multi-cultural exchanges under the Belt and Road Initiative.

Zhenjiang has issued many plans and policies to promote the development of cultural industries in recent years. However, the promotion and development of local culture in Zhenjiang is, on the whole, faced with many problems such as insufficient integration of cultural resources, low rate of development and utilization, lack of cultural brands, weak innovation ability in cultural industries, defective design of cultural and creative products, low market competitiveness and inadequate publicity. The cultural card of Zhenjiang has yet to be created.

\footnotetext{
*Corresponding author: 34892387@qq.com
} 


\section{DEVELOPMENT IDEAS FOR INNOVATIVE DESIGN OF ZHENJIANG CULTURAL AND CREATIVE PRODUCTS}

Zhenjiang is very rich in cultural resources including Zhenjiang ancient literature, science and technology, art culture, Zhenjiang language culture, Zhenjiang poetry culture, Zhenjiang folklore culture, Zhenjiang folk art culture, Zhenjiang religious culture, Zhenjiang landscape garden culture and Zhenjiang food culture. Among them, the most well-known ones include natural scenery such as Jinshan Hill, Beigushan Hill, Jiaoshan Hill, Nanshan Hill, Maoshan Hill and Baohuashan Hill which have the reputation of "the world's first landscape" and "urban forest". They can also be extended to the Tale of the White Serpent, the culture of Three Kingdoms, famous poetry, Taoism and Buddhism and other cultural elements. Wellknown stories or idioms include the Flooding of Jinshan Temple, Groom Invitation in the Ganlu Temple and the Beigu Tower Full of Scenery. In addition, the thousandyear-old Xijindu Ancient Street, Dream Pool Eassys by Shen Kuo and the three delicious food in Zhenjiang are all representative cultural elements of Zhenjiang. Development ideas for the innovative design of Zhenjiang cultural and creative products include in-depth excavation of such elements to present a cultural outlook of traditional and modern integration in the new era, the use of cultural and creative products, an art derivative form that integrates art, culture and products, to promote cultural transmission and economic development and meet the spiritual needs of consumers and the creation of a digital card of Zhenjiang urban culture with creative design, specifically including::

\subsection{Selection of key cultural resources in cultural and creative product design}

It is necessary to screen cultural resources and select the most well-known Zhenjiang cultural elements or the most representative and famous cultural elements of Zhenjiang during the design of Zhenjiang cultural and creative products, and create its unique digital cultural card with design to enhance the urban image and international reputation of Zhenjiang in the B\&R construction. The Guidance on Promoting the Development of Characteristic Cultural Industries jointly issued by the Ministry of Culture and the Ministry of Finance in 2014 clearly stated that the development of local cultural industries must follow the principles of adapting measures to local conditions and highlighting characteristics and the brand strategy, i.e. localization, characteristic construction and branding. The author believes that, with mountain forests as the key cultural element, including folklore and religious culture, Zhenjiang can not only form a cultural brand and highlight its cultural characteristics, but also avoid cultural conflicts in cross-cultural transmission during the B\&R cultural communication and promotion, as it has beautiful natural scenery and numerous famous mountains, which can also be extended to related cultural resources such as folklore and religious culture. The famous calligrapher $\mathrm{Mi} \mathrm{Fu}$ wrote "Urban Forest" in
Nanshan Hill, Zhenjiang over 1,000 years ago. Now we might as well focus on the theme for creative development and design of cultural and creative products.

\subsection{Cross-cultural background communication in cultural and creative product design}

It is also necessary to consider the cross-cultural transmission of local culture during the design of Zhenjiang local cultural and creative products based on the global background of the Belt and Road. As countries along the Belt and Road have diverse cultures, the cooperation and interaction at material and spiritual levels may cause cross-cultural conflicts or promote crosscultural integration. As far as the design of cultural and creative products is concerned, it is required to analyze the cultural tolerance of products and design factors that must be avoided at some point, and use the design of cultural and creative products to exert the guidance, integration and appeal of cultural transmission and exchange, attach local cultural characteristics of Zhenjiang to the products and make them accepted by the culture of others so as to realize cultural promotion and recognition and let Zhenjiang culture "go out". As a landscaped garden city, Zhenjiang has rich natural resources, pleasant and representative scenery and profound Buddhist cultural resources. Jinshan Hill, Jiaoshan Hill, Baohuashan Hill and Chuishan Hill are all related to Buddhism. The all-inclusive and open-minded feature of Buddhist culture is exactly an important condition for cultural exchange and promotion under the Belt and Road Initiative. Folklore such as the Tale of the White Serpent contains elements of Buddhism and love which are highly inclusive cultural elements in crosscultural promotion and are worth considering.

\subsection{Enriching design dimensions of cultural and creative products and integrating the market for a win-win situation}

The cultural manufacturing industry and the huge cultural consumer market have just started. We should revitalize and develop traditional culture by means of creation and design under the premise of grasping the pulse of the development of society and the times. The future design prospect is moving towards the integration of art, technology, culture, creation and industry. Cultural and creative products have huge market potential and future development space. As far as Zhenjiang cultural and creative products are concerned, Zhenjiang's own cultural resources have the potential to be tapped in depth. The proposal of cultural and creative industries is even more demanding. However, the development of local cultural industries in Zhenjiang cannot rely solely on cultural and creative products or be fully controlled by the government or design companies blindly. Comprehensive cooperation in many aspects is required. Meanwhile, cultural industries or projects such as tourism, network, convergence media, big data and educational activities can be integrated to enrich design dimensions of 
Zhenjiang cultural and creative products in order to develop the market of such products.

\section{INNOVATIVE DESIGN CASES OF ZHENJIANG CULTURAL AND CREATIVE PRODUCTS}

As a teacher of the industrial design discipline, the author has been committed to the research of cultural and creative products, especially the utilization of local cultural resources in Zhenjiang, exploring how to inject local cultural connotations of Zhenjiang into modern product design and make them a digital card of Zhenjiang culture. Some design achievements have been made in the teaching practice over the years. Design cases of some students will be analyzed below for discussion on the innovative design of Zhenjiang cultural and creative products.

\subsection{Cultural and creative product design with cultural elements of landscape gardens in Zhenjiang}

Shan Shui Jian: With the landscape of Zhenjiang as the prototype, the whole set of furniture presents a wellproportioned landscape scroll of Zhenjiang which is embraced by mountains on three sides and adjoining to the river on one side. In particular, the combination of Jinshan Hill, Beigushan Hill and Jiaoshan Hill lining up along the river in the urban area with the furniture based on the abstract technique, and the design method of 2D and 3D visual illusion give people a dynamic sense of river water flowing down, making people feel like being within the landscape. The design won the bronze prize in the 2017 Zhenjiang Cultural Relics Creative Design Competition ( Figures 1 and 2).

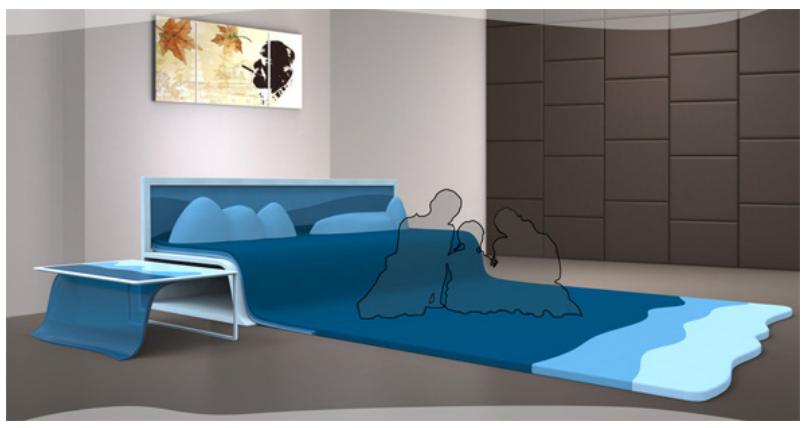

Figure 1 Shan Shui Jian furniture set
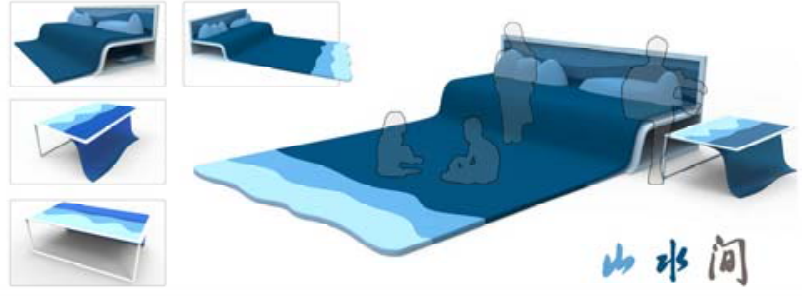

Figure 2 Shan Shui Jian furniture set

Yan Bo Jiang Shang: Jiaoshan Hill has been called a "calligraphy hill" in the past dynasties, which is full of literary spirit. The product is a set of multi-functional stationery accessories based on the shape of Jiaoshan Hill as a "floating jade in the river", integrating the river, hill, moon, cloud and crane elements. The two stationery accessories - brush washer and hanger are combined subtly with the lamp and incensory, forming a poetic scene of the Jiaoshan Hill under the moon. The product is both functional and decorative, providing a good experience for the literati. The design won the third prize of the Jiangsu Division of the 2018 National Industrial Design Competition for College Students (Figures 3 and 4).

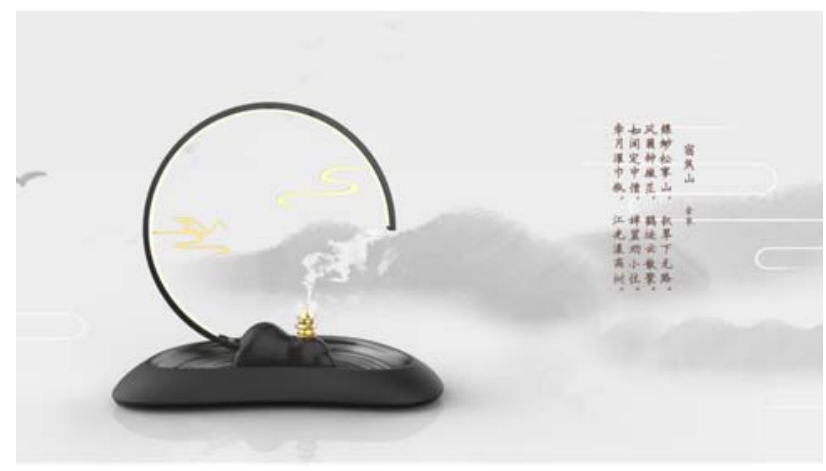

Figure 3 Yan Bo Jiang Shang multi-functional stationery accessories

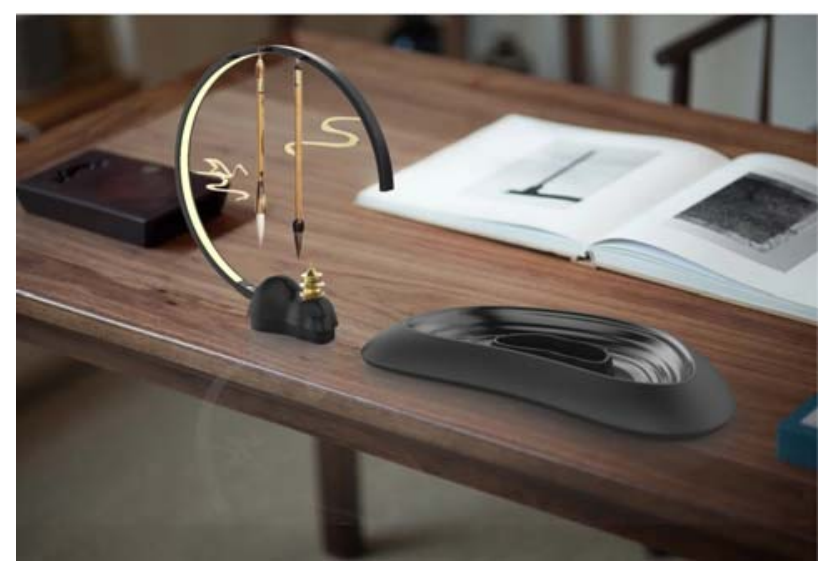

Figure 4 Yan Bo Jiang Shang multi-functional stationery accessories

\subsection{Cultural and creative product design with relicious cultural elements of Zhenjiang}

Green Hill and Cloud Sea Tea Set: The design elements come from Maoshan Taoist culture. The design is inspired by the Eight Diagrams, which is dominated by black and white. The teapot and the teacup are detachable and together form the Eight Diagrams. The concave and raised base plate is abstracted from the image of the cloud sea on the peak of Maoshan Hill (Figures 5 and 6). 


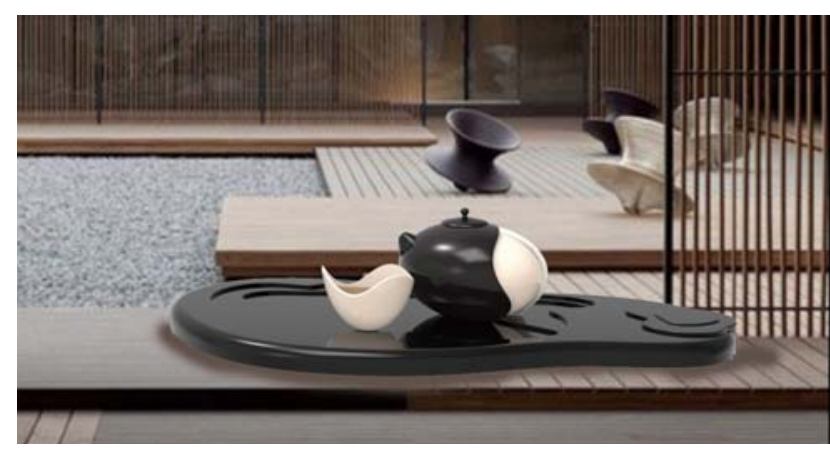

Figure 5 Green Hill and Cloud Sea Tea Set

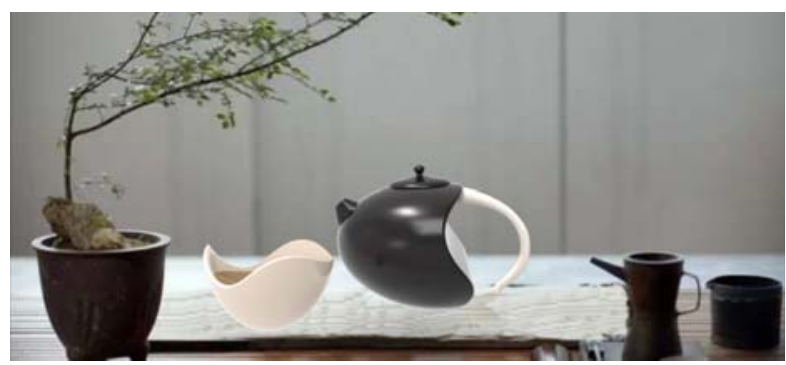

Figure 6 Green Hill and Cloud Sea Tea Set

Jinshan Hill with Fog and Rain: It is an ultrasonic humidifier with three different design elements in the annulus - mountain, water and tower. When the water mist diffuses slowly, it echoes with the huge and small mountains above, just like the flooding of Jinshan. The combination of motion and stillness and of virtuality and reality between the water mist and mountains makes people intoxicated. The moisture felt at the tip of the nose gives a feeling of lingering in the rain and mist of Jinshan. The dynamic and interesting scene of the flooding of Jinshan makes people feel like they are in the hill under the echo of the water mist and different scenes in the annulus. The design won the first prize of the Jiangsu Division of the 2018 National Industrial Design Competition for College Students (Figures 7 and 8).

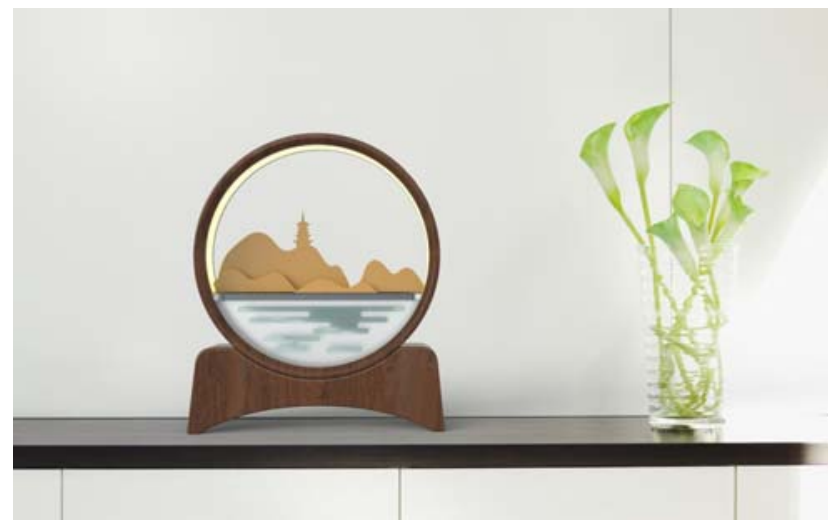

Figure 7 Jinshan Hill with Fog and Rain ultrasonic humidifier

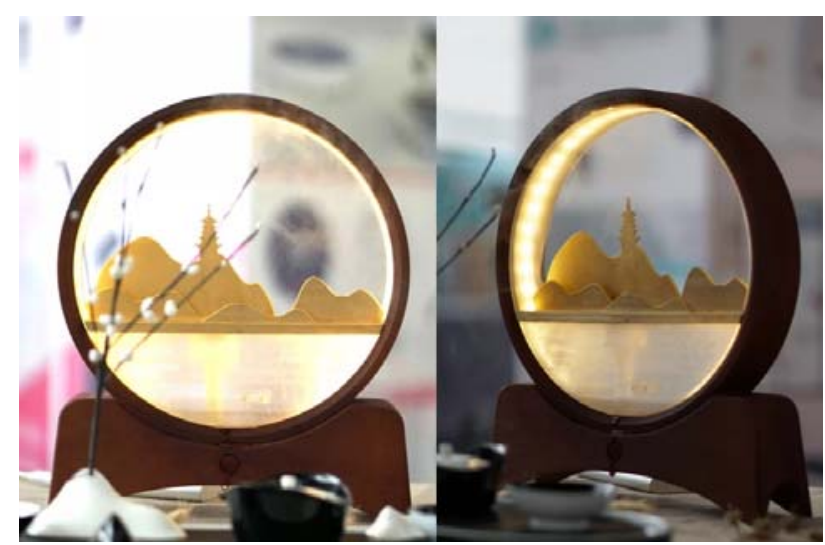

Figure 8 Jinshan Hill with Fog and Rain ultrasonic humidifier

\section{ConCLUSION}

The humanistic connotation of a city can not only reflect its cultural attractiveness, but also has the strong cohesion and radiation force to enhance international influence, expand external exchanges and attract overseas investment and talents at home and abroad. The creation of a digital card of Zhenjiang culture through design innovation with cultural and creative products as the entry point in the context of multi-cultural exchanges under the Belt and Road Initiative can help break through the relatively single form of local cultural promotion of Zhenjiang, expand its channels and facilitate crosscultural exchange and transmission to promote local culture of Zhenjiang to the world.

\section{REFERENCES}

1. Zhao Liqing. Research on the Realization Path of Cultural Exchange under the Belt and Road Strategy[J]. Academic Forum, 2016, (5)

2. Shuang Chuanxue. China's Cultural Opening Strategy under the View of the Belt and $\operatorname{Road}[\mathrm{J}]$. Dong Yue Tribune, 2016, (5)

3. Zhenjiang Municipal People's Government, Zhenjiang Committee of the Communist Party of China. Historical and Cultural City of Zhenjiang [M]. Jiangsu: Jiangsu University Press, 2016

4. Wang Shaopeng. "The Belt and Road" Initiative and Intercultural Communication[J]. Journal Of Shaanxi Academy Of Governance, 2016, (2)

5. He Qianyun. Study on Design Appraoch of Cultural and Creative Products based on Regional Life Style[D]. Wuhu: Anhui Polytechnic University, 2016

6. Lin Minghua, Yang Yongzhong. Creative Product Development Model: Promoting Chinese Creativity with Cultural Creativity [M]. Beijing: Economy \& Management Publishing House, 2014

7. Xie Shihai. Research on Cross-Cultural Product Design [D]. Nanjing: Nanjing University of Aeronautics and Astronautics, 2012. 
8. Zhong Lei, Li Yang. Cultural Creativity and Tourism Product Design [M]. Beijing: China Architecture \& Bulding Press, 2015
9. The Development of Zhenjiang Cultural Industry Needs to Rise to the Challenge[EB/OL]. http://zgjssw.jschina.com.cn, 2017-03-24 